\section{Pregnancy and risk of a traffic crash}

I read with great interest Redelmeier and colleagues' ${ }^{1}$ article on pregnancy and the risk of a traffic crash. The authors ${ }^{1}$ suggest that risk for a motor vehicle crash increases at the beginning of the second trimester of pregnancy and then subsides to baseline by the third trimester. The underlying assumption is that potential cognitive deficits or fatigue associated with the second trimester of pregnancy may account for this increased risk. However, a more obvious variable may account for these results. Adverse weather is a known factor in motor vehicle crashes, and crashes occur more frequently in the winter months. Similarly, the frequency of birth by month shows a trend toward a greater number of births in early and late summer. Counting backward, on average, most women will enter their second trimester during the winter months with the most adverse weather conditions, specifically January through March. In which month a crash occurs may be as, if not more, important than the stage of pregnancy.

\section{Jeffrey M. McKillop PhD}

Private practice, London, Ont.

\section{Reference}

1. Redelmeier DA, May SC, Thiruchelvam D, et al. Pregnancy and the risk of a traffic crash. CMAJ 2014;186:742-50.

CMAJ 2014. DOI:10.1503/cmaj.114-0068

Redelmeier and colleagues ${ }^{1}$ bring to attention an important issue. The authors ${ }^{1}$ define their outcome as a crash that results in a visit to an emergency department, identified using International Classification of Diseases codes related to vehicle crashes. However, unmasking bias (also referred to as surveillance bias) $)^{2}$ should be considered because of its potential contribution to the observed effect. Sackett ${ }^{3}$ explains unmasking (detection signal) bias:

An innocent exposure may become suspect if, rather than causing a disease, it causes a sign or symptom which precipitates a search for the disease.
Given the potential adverse outcomes of trauma during pregnancy, ${ }^{4}$ pregnant women may be more likely than nonpregnant women to be transported to hospital or admitted to hospital following a collision, regardless of their injury severity. ${ }^{5}$ The authors' 1 finding that pregnant women were less likely to be admitted to hospital than at baseline may suggest that women are visiting the emergency department out of caution for less severe injuries that may or may not require admission. In this study, pregnant women were more likely than at baseline to attend the emergency department following motor vehicle collisions even as passengers, further supporting this notion.

\section{Sarah Buchan MSc, Ariel Pulver MSc, Joel G. Ray MD MSc}

Dalla Lana School of Public Health

(Buchan, Pulver); St. Michael's Hospital

(Ray), Toronto, Ont.

\section{References}

1. Redelmeier DA, May SC, Thiruchelvam D, et al. Pregnancy and the risk of a traffic crash. CMAJ 2014; 186:742-50.

2. Haut ER, Pronovost PJ. Surveillance bias in outcomes reporting. JAMA 2011;305:2462-3.

3. Sackett DL. Bias in analytic research. J Chronic Dis 1979;32:51-63.

4. Vivian-Taylor J, Roberts CL, Chen JS, et al. Motor vehicle accidents during pregnancy: a populationbased study. BJOG 2012;119:499-503.

5. Weiss HB, Strotmeyer S. Characteristics of pregnant women in motor vehicle crashes. Inj Prev 2002;8: 207-10.

CMAJ 2014. DOI:10.1503/cmaj.114-0069

\section{The authors respond}

McKillop ${ }^{1}$ emphasizes that motor vehicle crash risks can vary depending on the weather, and that adverse weather is correlated with the Canadian winter. We agree, and this was our rationale for a secondary analysis comparing each individual's middle trimester of pregnancy to the same months exactly a year earlier. This analysis yielded a somewhat higher relative risk associated with pregnancy (odds ratio $=1.62$, 95\% confidence interval 1.45-1.82, $p<0.001$ ). Evidentially, our findings cannot be attributed to seasonal fluctuations in adverse weather. ${ }^{2}$

Buchan and collegues ${ }^{3}$ suggest that a woman's increased propensity to seek care while pregnant might bias our analysis. We tested this idea by examining three measures of crash severity during the middle trimester and baseline interval. We found that the frequency of a higher emergency triage score was increased for crashes during pregnancy (74\% v. $58 \%, p<0.001)$. The frequency of ambulance involvement was about the same ( $47 \%$ v. $45 \%, p=0.308)$ as was the frequency of admission ( $2.6 \%$ v. $3.2 \%, p=0.409)$. An increased propensity to seek care is unlikely to explain the magnitude of our findings.

Each letter ${ }^{1,3}$ also motivates points of clarification. McKillop ${ }^{1}$ is not perfectly correct in claiming that crashes occur more often in winter - only property damage crashes increase in the winter. Crashes that cause serious injury are more common during the summer. ${ }^{4,5}$ Buchan and colleagues ${ }^{3}$ are not perfectly correct in implying that crashes can be innocent exposures for pregnant women; instead, low-impact speeds can lead to placental separation, uterine rupture or diffuse axonal damage in the fetus. Case studies in obstetrics indicate that amniotic fluid does not perfectly protect a fetus in a crash. ${ }^{6,7}$

Donald A. Redelmeier MD MSHSR, Sharon C. May BSc, Deva Thiruchelvam MSc, Jon F. Barrett MD

Sunnybrook Health Sciences Centre (Redelmeier); University of Toronto (May); Institute for Clinical Evaluative Sciences (Thiruchelvam); Sunnybrook Research Institute (Barrett), Toronto, Ont.

\section{References}

1. McKillop JM. Pregnancy and risk of a traffic crash [letter]. 2014;186:1169.

2. Redelmeier DA. The exposure-crossover design is a new method for studying sustained changes in recurrent events. J Clin Epidemiol 2013;66: 955-63.

3. Buchan S, Pulver A, Ray JG. Pregnancy and risk of a traffic crash [letter]. 2014;186:1169. Redelmeier DA, Drucker A, Venkatesh V. Major trauma in pregnant women during the summer. $J$ Trauma 2005;59:112-6.

5. Ontario road safety annual report (ORSAR) 2010. Toronto: Ontario Ministry of Transportation; 2010.

6. Hayes B, Ryan S, Stephenson JB, et al. Cerebral palsy after maternal trauma in pregnancy. Dev Med Child Neurol 2007;49:700-6.

7. Weiss HB, Sauber-Schatz EK, Cook LJ. The epidemiology of pregnancy-associated emergency department injury visits and their impact on birth outcomes. Accid Anal Prev 2008;40:1088-95.

CMAJ 2014. DOI:10.1503/cmaj. 114-0070 